\title{
APPLICATION AND ESTIMATION OF WHEAT PRODUCTION EMULATION SYSTEM IN HEBEI PROVINCE
}

\author{
Shijuan $\mathrm{Li}^{1}$, Yeping Zhu ${ }^{*}$, Yan Xue ${ }^{1}$ \\ 1 Institute of Agricultural Information, China Academy of Agricultural Sciences, Beijing, P. \\ R. China 100081 \\ * Corresponding author, Address: Library 311, Agricultural Information Institute, Chinese \\ Academy of Agricultural Sciences, No.12 Zhongguancun South Street, Beijing, 100081, P. \\ R. China, Tel:+86-10-82103120, Fax:+86-10-82103120, Email: zhuyp@mail.caas.net.cn
}

\begin{abstract}
In according with wheat ecophysiological characteristics, the author applied technologies of system engineering method, crop simulation and computer to build wheat developing process cooperative models including growth model, developmental phase models, water balance model and nitrogen balance model etc. with the support of basic data such as variety characteristics, weather data, soil level and cultivation management, then further constructed Wheat Production Emulation System (WPES) with several additional functions such as determining variety characteristic parameters, deciding the planting design, simulating wheat phenology stages and production features, warning of the nitrogen leaching in advance, simulating the water and nitrogen deficit degree and wheat growth three-dimensional display. This system was validated and calibrated through actual experiment for four wheat growing seasons in Hebei province. Predicted yield and biomass were significantly correlated with observed data (R2>0.47), and the Root Mean Square Error were $5.89 \%$ and $8.94 \%$ of its observed average yield and biomass. The results verified its strong mechanism and prediction performance as well as its universal adaptation.
\end{abstract}

Keywords: winter wheat, emulation system, growth and development, simulation model

Please use the following format when citing this chapter:

Li, S., Zhu, Y. and Xue, Y., 2009, in IFIP International Federation for Information Processing, Volume 293, Computer and Computing Technologies in Agriculture II, Volume 1, eds. D. Li, Z. Chunjiang, (Boston: Springer), pp. 79-88. 


\section{INTRODUCTION}

Growing with the development of computer technology, system analysis theory and agricultural scientific research, crop simulation model has been becoming the core of agricultural production management and resource optimization management, and the basis of precision agriculture which is implemented now in China. After 50 years evolvement crop simulation model becomes more mature possesses of more mechanism. America, Holand, England and Australia developed many crop models, some of which had been used in agriculture successfully. DSSAT of America including many famous models such as CERES and GROPGRO etc. can simulate 17 crops, and GROPGRO can evaluate the effect of more than 20 insect pests (Hoogenboom, et al, 1999). APSIM developed by Australia integrates different crop models to a common platform using for reference among subjects, and can simulate crop, vegetable and weed etc. (McCown, et al, 1996). Wageningen Univerdity and Research Center exploited SUCROS series models including MACROS, BACROS and WOFOST model. Besides the EPIC model can evaluate climate change and its effect on agriculture (Williams, et al, 1989). In the process of model application, model validation is an important work. Many researcher have done a lot of experiments and simulations in model test, introduction and modification. Malone and Heilman (2007) appraised the Root Zone Water Quality Model (RZWQM) response to different $\mathrm{N}$ management strategies, and results indicated RZWQM model can quantify the effects of nitrogen management on corn yield and nitrate concentration after calibration and thorough testing, and Predicted corn yield and nitrate- $\mathrm{N}$ concentration were significantly correlated with observed data, and the author thought planting wheat following corn and soybean may reduce $\mathrm{N}$ loss. A cropping system simulation model (CropSyst) was evaluated by Benli et al (2007) for its ability to simulate growth, biomass, grain yield and evapotranspiration (ET) of wheat sown early with supplemental irrigation. Results showed its good forecast performance, and model predicted better the seasonal ET under full supplemental irrigated conditions thanunder rainfed conditions. The model was run to simulate supplemental irrigation and rainfed yield using 20 years weather data. Data showed wheat grain yield could be improved with applying water, and yield increase depended on irrigation time.

Now crop simulation model mainly is used to forecast yield with typical application such as studying world food and agri-ecological belt, forecasting regional yield, evaluating the effects of environment and social economy changes on agriculture. Crop model develops for multi application with the increase of social demand. Moriondo et al integrated NDVI data taken from satellite platforms and wheat development stages model (CROPSYST) to estimate regional yield. The application results obtained in two Italian provinces showed the high accuracy of the method in estimating wheat yield 
at the provincial level (Moriondo, et al, 2007). Greenwald et al introduced TUV model to crop productivity model (CERES) to calculate photosynthesis active radiation (Greenwald and Bergin, 2006). The model InfoCrop integrated from many submodels can simulate crop growth, development stages, water and nitrogen balance as well as the effect of temperature, waterlog, frost, plant diseases and insect pests and greenhouse gas such as $\mathrm{CO}_{2}, \mathrm{CH}_{4}, \mathrm{~N}_{2} \mathrm{O}$ (Aggarwa et al, 8). Along with the study of crop model increasingly day by day, forecast for diseases and insect pests attracts more and more attention. Some information system in America and Europe can be used for investigating and predicting insect pests. Holand and Germany specially developed wheat plant protection decision-support system EPIPRE and PRO-PLANT (Forrer, 1992; Frahm, et al, 1993). A simulation model of weed growth and competition was developed and parameterised for 15 autumn germinating weed species common in UK by Storkey and Cussans (2007), which was validated over 2 years and used to explore possible management options for reconciling the conservation of in-field biodiversity with winter wheat production. There were large differences in the model parameters between the species and the hypothesis that weed growth and competition could be modeled on the level of weed functional group was rejected.

China started crop simulation model study since 1980s. After introducing, analyzing and improving foreign crop models, researchers developed a lot of application systems. Some units exploited their own crop simulation model. For example, Zhao chunjiang et al (1997) constructed wheat management expert system based model for Beijing; Soil and Fertilizer Institute of Chinese Academy of Agricultural Sciences developed wheat and maize optimal fertilization expert system of Yucheng county on Huanghuai Plain; Nanjing Agricultural University integrated wheat growth model and expert system to wheat intelligent management and decision-making system (Zhu, et al, 2004); Jiangsu Academy of Agricultural Sciences constructed rice cultivational simulation-optimization-decision daking system (Gao, et al, 1992). On the basis of past researches (Li, et al, 2007) and studying wheat development discipline deeply, Wheat Production Emulation System based on cooperative models was built using system engineering theory, computer technology and modeling method in order to realize digital wheat production management.

\section{WHEAT PRODUCTION EMULATION SYSTEM}

Based on the past studies, we collected related literatures and agronomic expert information in a large scale, then designed wheat cooperative models 
in accordance with wheat growth and development discipline, and combined the models with corresponding database and repository, and constitute Wheat Production Emulation System (MPES) using technologies of system engineering theory, software engineering theory, computer and animation and image processing. The system consists of cooperative models, database and interface etc. Next its components will be elaborated. Using programming language Visual $\mathrm{C}++$ and Visual Basic 6.0 to design system interface, MPES was developed on the operation system of Windows 2000 server. Database was built in Access 2000, and forms and graphs output was carried out by Teechart control unit. The models integrated according to $\mathrm{COM}$ standard by programming language $\mathrm{Visual} \mathrm{C}++$ are main content of MPES. In addition, databases, variety parameter test module and weather creation module programmed by Visual $\mathrm{C}++$ are included. Basic parameters database saves variety information, soil data and agronomic management. Weather data day by day are kept in weather database. The simulation and predicting results of models were transported into result database. Interface functions implement the data transfer between models and databases.

\subsection{Databases}

Basic parameter database consists of information about location, fertilizer type, fertilizer management, irrigation management, cultivation variety, phenology data, soil texture and soil parameter, among which phenology data, as actual experiment data, is used to determine the genetic characteristic parameters for certain variety; soil parameters contain former crop remains information, water content before sowing, and organic matter percent, volume weight, $\mathrm{NH}_{4}-\mathrm{N}, \mathrm{NO}_{3}-\mathrm{N}$ and $\mathrm{PH}$ of every soil layer. The datum of daily highest temperature, lowest temperature, rain and solar radiation or sunlight time input by user are saved in weather database. The qualitatively knowledge about wheat cultivation that can not be analyzed quantitatively through models are expressed with production rule and concluded into knowledge base, which solves the practical problems by means of reasoning machine according to users' input and aim. Results database stores the simulation results from cooperative models and decision layer, and the tables are set on the basis of the output menus.

\subsection{Cooperative modes}

Applying system engineering, computer technology and model method, and based on the past modeling experiences, agronomic knowledge and experimental data, deep analysis on wheat growth and development discipline, we quantified wheat growth and its effective factors to several 
models which realized valid cooperation. The following gives details of the main cooperative models and their functions, respectively.

Wheat growth model computes LAI, Light Interception, photosynthesis, and dry matter production and distribution in wheat, and calculates $\mathrm{N}$ uptake and distribution. Wheat development is divided into 8 stages in wheat development model: from sowing to germination, from germination to seeding emergence, from seeding emergence to juvenile stage, from juvenile stage to jointing stage, from jointing stage to silking stage, from silking stage to beginning of grain filling, from beginning of grain filling to physiological maturity. Temperature, water, photoperiod and genetic parameter restrict the replacement of development stages. Genetic parameter can be input by user or decided automatically by parameter determination program in system. Water balance model is built to simulate water leakage, runoff, soil evaporation, plant transpiration and root water absorption in each soil layer according to water movement rules, soil water status and wheat absorption characteristic adopting Priestly-Taylor equation and SCS Curve Number Method. $\mathrm{N}$ balance model mainly simulates $\mathrm{N}$ mineralization and fixation of organic matter in soil, $\mathrm{N}$ losses and uptake by crop. $\mathrm{N}$ deficit index calculated by the model affects directly daily accumulated value of wheat dry matter and LAI. This model considers the amount of nitrate leached out of wheat root zone (here define it as 2 meters) with water movement, and evaluated possible effects of the leached nitrate on groundwater. The effects on main wheat quality (protein, starch and fat) of variety trait, weather, cultivation management and nutrition are analyzed by grain quality model which deducted the algorithm with Logistic equation by drawing up the relation between quality and impact factors such as density, days after grainfilling, water and nutrition. In order to observe wheat growth and yield formation directly, 3D visualization model was developed ob the basis of agronomic shape knowledge, image and 3D animation technology, and the simulation results. 


\subsection{System interface}

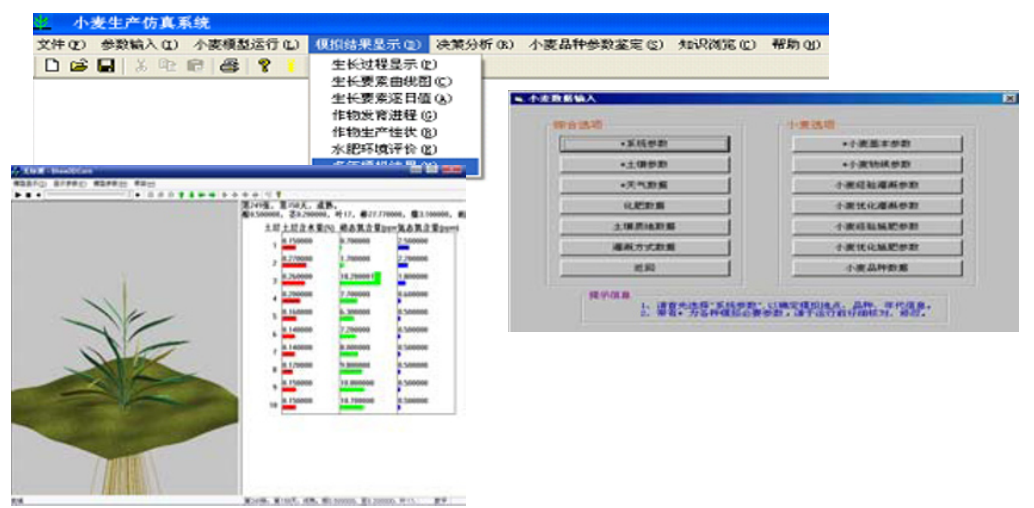

Fig. 13D visualization for wheat growth

User contacts system or models by friendly and beautiful system interface (Fig. 1), which includes data input and results showed by form, graph for the daily data of more than 40 indexes and $3 \mathrm{D}$ visualization, and is easy to be operated and understood. The system reduces the demanding parameters that are not easy to get for user. 3D visualization show simulates the shape changes of seed, root, stem, leaf, spike and female flowers from sowing to maturity, and the corresponding content for soil water, $\mathrm{NO}_{3}-\mathrm{N}$ and $\mathrm{NH}_{4}-\mathrm{N}$ are displayed on the right screen simultaneously. 3D visualization for wheat growth is shown in Fig. 2.
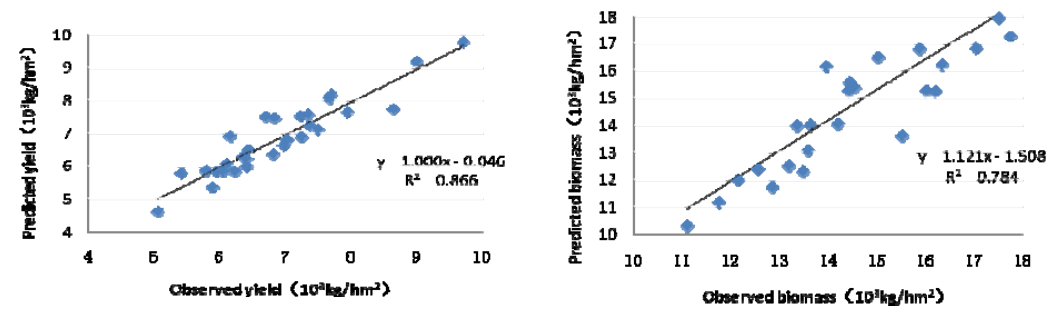

Fig. 2 Comparison of observed yield and biomass vs. predicted data

\subsection{System functions}

Digital wheat production including yield and yield components prediction, quality formation forecast, water and nitrogen dynamics, $\mathrm{N}$ and water taken up and utilization by the crop, and N loss can be simulated with WPES using various varieties under different location and soil fertility levels with one day as time step. The system expresses the simulation results directly with form and figure. It gives anticipative target yield and quality, variety choose, 
sowing date and density determination, fertilizer and water management according to user's requirement and biological environment of decision location. Based on cooperative models, system analyzes wheat variety, water and nutrition status, weather resource and offers assistant decision-making, such as the suggestions on optimal variety, sowing date and density, the amount and time of irrigation and fertilizer. In the meantime, combining with simulation results from cooperative models related to wheat growth and configuration, 3D visualization simulates wheat morphological development vividly using animation and image processing technologies. System functions are as following: predicting wheat yield and development, estimating water and nitrogen utilization and nitrogen loss, recommending water and nitrogen management scheme, evaluating cost-benefit, offering assistant decision-making and showing 3D wheat growth.

\section{APPLICATION EXAMPLE OF WPES IN HEBEI PROVINCE}

WPES was calibrated and validated with data gotten from Wuqiao experimental station in Hebei province which existed in Huang-huai-hai plain, China. Cooperative models of WPES consist of 5 variety genetic characteristic parameters, i. e. relative vernalization sensitivity, relative photoperiod sensitivity, relative value of conversion factor for grain number per unit stem weight relative duration of grain filling phase, relative value of maximum possible daily growth rate of a kernel, relative value for potential dry weight of a single stem and ear at anthesis. Before the system can be used, user should validate model according to weather data and observed value to determine variety characteristic parameters. Weather data include daily maximum temperature, minimum temperature, total radiation and rain.

There are experimentation data for four seasons in whole. Detailed design materials and methods were described by references (Zhou Shunli, et al, 2002; Wang Qixian,2001; Li Jianmin et al, 2000). This paper just makes use of partial data to prove model system mentioned above. In 1994-1995 and 1995-1996 seasons four irrigation treatments including different irrigation frequency and equal irrigation quota were set up with wheat variety 95021 , and one treatment was adopted to validate model for every season and the rest were used to model test. In 1997-1998 and 2002-2003 seasons effect of four nitrogen gradients $(0,90,180,270 \mathrm{kgN}$ ha-1) on four varieties $(95021$, Heng 4041, 6029 and Shannong 45) was tested. We validated model using one treatment for every variety and season to determine genetic parameters, and used the remainder to test model or system. 
After running WPES the simulated yield and above biomass for four seasons were achieved. Fig. 3 indicates observed yield and biomass relate predicted data significantly at $\alpha=0.01$. The relative coefficient is 0.931 for predicted and simulated yield, 0.832 for predicted and simulated biomass. RMSEs that can reflect simulation error of yield and biomass are $406.4 \mathrm{~kg}$ ha-1 and $1340.4 \mathrm{~kg}$ ha-1 respectively. The ratio of RMSE to average observed data (i. e. average RMSE), which expresses deviation more accurately are $5.89 \%$ and $8.94 \%$ respectively. Although the deviation for predicting yield and biomass less than $10 \%$, it's obvious the system forecasts yield better than biomass. The possible reason is system simulates biomass including dead tillers and dry leaves which can't be contained in observed biomass. Meanwhile complicated factors from the randomicity of field production affect wheat growth, but many of them are not possible to be considered by crop model. With the further improvement holding more environment factors to perfect model will enhance prediction ability of crop model.

\section{CONCLUSION}

Taking wheat as study object, analyzing the relationship among crop, environment and management practice, applying system engineering theory, dynamic simulation and visualization technologies, wheat simulation model based on growth development was constructed. Then authors designed WPES and realized wheat 3D visualization with component object programming (COM) standard. The aim of this study is to forecast wheat production system accurately, manage and monitor wheat growth scientifically and timely.

WPES includes wheat growth model, development model, water and nitrogen balance model, grain quality model, economic analysis model and $3 \mathrm{D}$ visualization model as well as databases and knowledge base. Using experimental data for four seasons of same location in Hebei province to calibrate and validate the system proved its good prediction performance with less than $10 \%$ simulation deviation for yield and biomass. And the yield had more accuracy than biomass. Of course it is far from enough for model validation data with one location. Though the parameters were determined and corrected with field data from Hebei, Shandong and Beijing etc. which plant wheat as a main grain crop, we will improve and perfect WPES according to the data from demonstration stations which keep frequent communication and cooperation with us. After the system achieves high accuracy of predicting yield and biomass, the water and nitrogen balance will be validated. 
Confined to existing agricultural knowledge, WPES considers mainly such eco-physiology processes as carton balance, water and nitrogen balance, and their mutual action. Since agricultural system is a dynamic and complicated multi-factor system, model system must include more impact factors to the full in order to approach actual production system such as the effect of phosphate and potassa on wheat growth and the coupling between fertilizers, harmfulness of plant diseases and insect pests and the pesticide effect. All these need agricultural researchers and software designers to work hard together.

\section{ACKNOWLEDGEMENTS}

Financial supports by Digital Agriculture Program of State High-tech Research and Development Project of China(No. 2006AA10Z220, 2007AA10Z237), and by National Scientific and Technical Supporting Programs Funded by Ministry of Science and Technology of China(2006BAD10A12) and Special Fund of Basic Scientific Research and Operation Foundation for Commonweal Scientific Research Institutes (2008J-5-06, 2008J-1-10) are gratefully acknowledged, We also pay thanks to staff of Dezhou Bureau of Agriculture of Shandong province and Climatic Data Center of National Meteorological Information Center of China Meteorological Administration which provided the required experimental and weather data at full steam.

\section{REFERENCES}

B. Benli, M. Pala, C. Stockle, T. Oweis, 2007, Assessment of winter wheat production under early sowing with supplemental irrigation in a cold highland environment using CropSyst simulation model, Agric. Water Manage. In Press.

Gao Liangzhi, Jin Zhiqing, Huang Yao, et al. Rice Cultivational Simulation-OptimizationDecision Making System (RCSODS). Beijing: China Agricultural Scientech Press, 1992.(inChinese)

G.Hoogenboom, P.W.Wilkens, P.K. Thornton, et al. 1999. Decision support system for agrotechnology transfer v3.5. In: Hoogenboom, G., Wilkens, P.W., Tsuji, G.Y. (Eds.), DSSAT version 3, vol. 4 (ISBN 1-886684-04-9). University of Hawaii, Honolulu, HI, pp. $1-36$.

H. R. Forrer, 1992, Experiences with the cereal disease forecast system EPIPRE in Switzerland and prospects for the use of diagnostics to monitor the disease state. Brighton Crop Protection Conference, Pests and Diseases , (2): 711 720.

J. Frahm and T. Volk, 1993, Pro_Plant - a computer-based decision support system for cereal disease control. Bulletin OEPP/EPPO Bulletin, 23, 685-694. 
J. R. Williams, C. A. Jones, J.R.Kiniry, et al. 1989, The EPIC Crop Growth Model.. Trans. ASAE 32(2): 497-511.

Jonathan Storkey, John W. Cussans, 2007, Reconciling the conservation of in-field biodiversity with crop production using a simulation model of weed growth and competition, Agriculture, Ecosystems and Environment, 122, 173-182.

Li Jianmin, Zhou Dianxi, Wang Pu, et al. Winter wheat cultivation technique with highefficiency utilization for water and nitrogen, Beijing: China Agricultural University Publishers, 2000. (In Chinese)

M. Moriondo, F. Maselli b, M. Bindi, 2007, A simple model of regional wheat yield based on NDVI data, Europ. J. Agronomy 26, 266-274.

P. K. Aggarwal, B. Banerjee, M.G. Daryaei, el al., 2005, InfoCrop: a dynamic simulation model for the assessment of crop yields, losses due to pests, and environmental impact of agro-ecosystems in tropical environments. I. Model description. Agricultural System, 89: 47-67.

R. L. McCown, G. L. Hammer, J. N. G. Hargreaves, et al. 1996. APSIM: a novel software system for model development, model testing and simulation in agricultural systems research. Agricultural Systems 50, 255-271.

R.W. Malone, L. Ma, P. Heilman, 2007, Simulated N management effects on corn yield and tile-drainage nitrate loss, Geoderma,140, 272 - 283.

Roby Greenwald, M.H. Bergin, Jin Xu et al, 2006, The influence of aerosols on the crop production:a study using the CERES crop model, Agricultural Systems, 89: 390 - 413.

Shijuan Li, Yeping Zhu, Dingchun Yan, Study on digital maize management system based on model, Progress of information technology in agriculture: proceeding on intelligent information technology in agriculture(ISSITA), Edited by Chunjiang Zhao, China agricultural science and technology press, October 26-29,2007,Beijing,China.pp: 240-243

Wang Qixian, Study on grain yield and quality formation of summer corn nongda 108 regulated by nitrogen application strategy, Beijing: College of Agriculture and biotechnology, China Agricultural University, 2001.

Zhao Chuanjiang, Zhu Dehui, Li Hongxiang, et al, Study on intelligent expert system of wheat cultivation management and its application. Scientia Agricultura Sinica, 1997, 30(5):42-49.(in Chinese)

Zhou Shunli, Zhang Fusuo, Wang Xingren, Study on differences in nitrogen nutrition between winter wheat varieties in response, uptake to nitrogen and associated depletion of soil nitrate, Scientia Agricultura Sinica, 2002,35(6):667-672.(In Chinese)

Zhu Yan, Cao Weixing, WANG Qimeng, A knowledge model- and growth model-based decision support system for wheat management, Scientia Agricultura Sinica, 2004,37 (6):814-820 